\title{
The European Journal of Clinical Microbiology and Infectious Diseases: quality and quantity in 2013
}

\author{
W. van Leeuwen • A. van Belkum
}

Received: 9 December 2012 / Accepted: 10 December 2012 / Published online: 23 December 2012

(C) Springer-Verlag Berlin Heidelberg 2012

The European Journal of Clinical Microbiology and Infectious Diseases (EJCMID) aims to publish experimental scientific documents primarily dealing with: (1) the epidemiology of microbes and microbial virulence genes; (2) the genetics and phenotypes of host susceptibility towards microbial infections; (3) animal models of microbial infections; and (4) the imaging of microbial infections. Over the past 5 years, the EJCMID has shown a healthy growth. The journal, published by Springer Verlag, has experienced a doubling in the number of submissions in recent years. We now receive a consistent number of approximately 900 submissions per year and the overall quality of the generally well-written papers offered for peer review is clearly increasing. It is gratifying to see a growing fraction of these papers originate from China, India, and other emerging economies. Unfortunately, such growth does not change the fact that, for reasons of comparative quality assessment among the manuscripts and also simply the printing volume which we have available, we will still have to reject $80 \%$ of the papers offered. Immediate rejection is an important part of that: we select the papers which are least likely to withstand rigorous peer review at an early stage, thereby, offering a quick response to the authors. This happens in about $65 \%$ of the current submissions. We are sure that, over the past year, you have witnessed the consequent increase in the volume of our EJCMID issues and some of you, being authors of these papers, will have experienced an irritating backlog in the speed with which we produce manuscripts visualized on paper in the regular issues. We hope that this is compensated for by a

\footnotetext{
W. van Leeuwen

Department of Clinical Microbiology and Infectious Diseases,

Erasmus MC, 's Gravendijkwal 230,

3015 CE Rotterdam, The Netherlands

A. van Belkum $(\bowtie)$

R\&D Microbiology, bioMérieux, 3, Route de Port Michaud,

58390 La Balme Les Grottes, France

e-mail: alex.vanbelkum@biomerieux.com
}

speedy online availability system that is, to date, very significantly faster than our "paper publishing".

Obviously, an increase in the publication volume drives the need for more scientific, practical, and managerial support. This is why a dedicated review editor was appointed, Dr. Willem van Leeuwen. Managing reviews is an important job and, in modern publishing, it is often the reviews that are a key driving force for augmentation of the impact factor (IF) of a journal. We published significantly more reviews over the past two years than in the years before, and we anticipate a clear effect of this success on the new IF for EJCMID to be published in June 2013. Next to appointing a review manager, we also "rejuvenated" the Editorial Board a little and take this opportunity to, once more, extend our gratitude to the now replaced members of the board, some of whom had served the EJCMID for an extended period of time. We thank all of these individuals for their editorial help, for reviewing the large numbers of submitted manuscripts, and, most importantly, for helping to promote the EJCMID in a variety of manners. Many of the former board members regularly published in the EJCMID and, again, this surely helped to get the journal where it is today. We welcome the new members of our board and we hope that we can profit from their expertise, as we have profited from the expertise of the former members.

An increase in the volume of published scientific papers does not always automatically result in a rise in the overall quality of the journal itself. However, we have noted that the number of citations to items published in the EJCMID has been strongly increasing from $2006(n=334)$ to $2009(n=$ $605)$. Apparently, the doubling in volume resulted in a concomitant doubling in the number of citations by other authors, indicating that, although the volume was magnified, the quality remained the same, at least. It has to be emphasized that the real effect of the increased output on scientific value will only be properly reflected by the IF to be published in 2013 and 2014. Over the past 5 years, the IF 
has already evolved positively: in 2011, the score was 2.859 , with a 5 -year IF of 2.852 . However, even today, we are able to corroborate the good quality of the papers published on the basis of the number of specific downloads. As a sign of appreciation to the authors of these papers, we make the PDFs freely accessible via our journal website [1-3]. For 2013 , we foresee being able to publish on the order of 180 200 manuscripts. This will slightly reduce the volume of the journal, but we are sure that, on average, we will be publishing really the best papers that will be submitted to the EJCMID over the coming year. We also foresee a clear reduction in the paper printing backlog.

The value of the scientific content of the EJCMID is directly determined by the quality of the manuscript reviews that are received before a decision to accept or reject a manuscript for publication is formulated. In this regard, we are $100 \%$ dependent on the scientific insight, knowledge, and professionalism of our reviewers. For several reasons, it is becoming more challenging to identify appropriate reviewers and motivate them into doing a good or, preferably, excellent job. On behalf of the EJCMID, we hereby want to acknowledge and thank all our past reviewers for their exceptional and voluntary work and dedication. In addition, a journal will probably not survive without the dedication of editorial assistants and other professionals.
We here thank Edline Cunanan and Friederike Klein for their indispensable and hard work in support of the manuscript management.

A final word of gratitude to you, our readership: we hope that you, like us, enjoy browsing journal content and selecting those papers that interest you the most for more thorough coverage. Journals are developed for their readership and we hope that you will contact us proactively if something is not to your liking. An occasional compliment will be well received also...

\section{References}

1. Adler A, Yaniv I, Samra Z, Yacobovich J, Fisher S, Avrahami G, Levy I (2006) Exserohilum: an emerging human pathogen. Eur J Clin Microbiol Infect Dis 25(4):247-253

2. Dunne WM Jr, Westblade LF, Ford B (2012) Next-generation and whole-genome sequencing in the diagnostic clinical microbiology laboratory. Eur J Clin Microbiol Infect Dis 31(8):1719-1726. Epub 2012 Jun 8

3. Gable MS, Gavali S, Radner A, Tilley DH, Lee B, Dyner L, Collins A, Dengel A, Dalmau J, Glaser CA (2009) Anti-NMDA receptor encephalitis: report of ten cases and comparison with viral encephalitis. Eur J Clin Microbiol Infect Dis 28(12):1421-1429. Epub 2009 Aug 29 